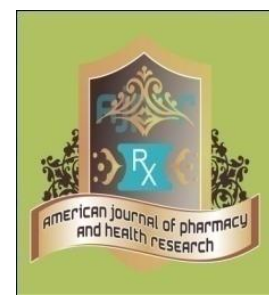

\title{
A Prospective Study Of Prescription Pattern and Assessing the Psychiatric Co-Morbidities In Dementia Patients In A Tertiary Care Hospital In South Kerala
}

\author{
Neethu $\mathbf{J}^{1 *}$, Aranya K Sreekumar ${ }^{1}$, Jibin John ${ }^{1}$, Kavya Shyam $^{1}$, Reshma S Reghu ${ }^{2}$, \\ Prasobh GR ${ }^{3}$ \\ 1.Associate professor, Department of pharmacy practice, Sreekrishna college of pharmacy \\ and research centre, Thiruvananthapuram, Kerala, India \\ 2. Fifth year Pharm D students, Sreekrishna college of pharmacy and research centre, \\ Thiruvananthapuram, Kerala, India \\ 3. Principal, Head Of Department of pharmacy practice, Sreekrishna college of pharmacy \\ and research centre, Thiruvananthapuram, Kerala, India
}

\begin{abstract}
Dementia is one of the most common disorders among elderly patients, Worldwide 7.7 million new cases of dementia were anticipated each year, implying one new case every 4.1 seconds. The aim of the study is to assess the psychiatric co morbidity and prescribing pattern in a tertiary care hospital in south India. This was an Prospective Observational Study conducted at tertiary care hospital. Prospective data was collected from outpatient and inpatient department. Out of 16 patients the common type of dementia reported was Alzheimer's disease found in ,56.3\% of the cases followed by vascular dementia and the prescribed drugs were Memantine (37.5\%) is the prescribed drug for most of the dementia cases followed by donepezil (25\%), Memantine + donepezil combination (18.75\%), Rivastigmine (12.5\%), Memantine + Rivastigmine combination (6.2\%). The common type of dementia reported was Alzheimers and Memantine was the most commonly prescribed drug in mono-therapy and among combination therapy Memantinedonepezil combination was mostly prescribed.
\end{abstract}

Keywords: dementia, prescribing pattern, psychiatric co morbidity

Please cite this article as: Neethu J et al., A Prospective Study Of Prescription Pattern and Assessing the Psychiatric Co-Morbidities In Dementia Patients In A Tertiary Care Hospital In South Kerala. American Journal of Pharmacy \& Health Research 2020. 
*Corresponding Author Email: neeth245@gmail.com

Received 16 August 2020, Accepted 06 September 2020

\section{INTRODUCTION}

Dementia is defined as an acquired deterioration in cognitive abilities that impairs the successful performance of activities of daily living . Memory is the most common cognitive ability lost with dementia. In addition to memory, other mental faculties were affected; these include language , visuospatial ability, calculation, judgment and problem solving. Dementia syndromes results from disruption of specific large scale neuronal networks, the location and severity of synaptic and neuronal loss combine to produce a clinical features. Behaviour and mood are modulated by noradrenergic, serotonergic and dopaminergic pathways whereas the cholinergic signalling is critical for attention and memory functions. ${ }^{1}$

The number of people living with dementia worldwide was estimated at 47.47 million as of 2015 , reaching 75.63 million in 2030 and 135.46 million in $2050^{2}$. From 2015 to 2050, numbers of people living with dementia will have increased slightly less than twofold in Europe, somewhat more than twofold in north America, threefold in Asia, and fourfold in Latin America and Africa. While $37 \%$ of the people living with dementia live in high-income countries, $63 \%$ live in low and middle-income countries. The incidence of dementia increased exponentially with increasing age, based on the available estimates for the global incidence of dementia dating from $2010^{3} .7 .7$ million new cases of dementia are reported each year worldwide, implying one new case every 4.1 seconds. This means that there were 3.6 million (46\%) new cases per year in Asia, 2.3 million (31\%) in Europe, 1.2 million (16\%) in the Americas, and 0.5 million (7\%) in Africa. It is expected that the burden of dementia will be increasing in developing countries due to increase in longevity and increasing prevalence of risk factors such as hypertension and stroke. In India 1.8 million people are affected with dementia ${ }^{3}$.

Alzheimers dementia begins in the transentorrhinal region spreads to the hippocampus and then moves to lateral, posterior, temporal and parietal neocortex , eventually causing more widespread degeneration. Vascular dementia is associated with focal damage in random network of cortical and subcortical regions or white matter tract that disconnect nodes within disturbed networks. patients with dementia that begins in frontal or subcortical regions such as fronto-temporal dementia or Huntigton's disease are less likely to begin with memory problems and more likely to have difficulties with mood and behaviour ${ }^{1}$. 
The treatment of dementia is basically directed towards management of cognitive and Behavioural symptoms of dementia. Particularly effective treatments are available for most common symptoms of dementia. Acetylcholinesterase inhibitors such as Donepezil, Rivastigmine, and Galantamine have been recommended to be used in mild to moderate cases of dementia while NMDA receptor antagonist Memantine is the only drug recommended for severe cases of dementia. The pathologic action of Donepezil, Rivastigmine and Galantamine is inhibition of the cholinesterase, primarily acetyl choline-esterase, with the resulting increase in cerebral acetyl choline level. Memantine appears to acts by blocking over-excited N-Methyl D-Aspartate (NMDA) glutamate receptor ${ }^{1}$.

With increasing life expectancy, the prevalence of dementia will increase dramatically in the next few decades, and will have a phenomenal emotional and economic impact. Thus cognitive impairment and dementia are one among the major public health concerns of the $21^{\text {st }}$ century. In this context there seems to be scarcity of data regarding dementia. This study highlights the present scenario of dementia in relation to epidemiology, psychiatric co morbidity and drug utilization pattern in a tertiary care hospital in south kerala ${ }^{2-4}$.

Neuropsychiatric and social deficits also seen in many subtypes of dementia resulting in depression, apathy, hallucinations, delusions, agitation, insomnia and disinhibition. The most common forms of dementia are progressive but some are static and unchanging or fluctuate from day to day or even minute ${ }^{4}$.

\section{MATERIALS AND METHOD}

All relevant information regarding the study will be collected from case records and direct interview with the caregivers in the presence of the physician. Data from patients or caregiver will be collected by using a specially designed proforma.

Pharmacotherapy data (indication, dose, posology, scheduling, and reports on the access to medicines) will be collected from the medical prescription, patient diary and all medicines (overthe-counter and prescription medicines) brought by the patient to the appointment with the physician.

The patients or care taker will then be educated about the disease and medication. To assess the patient condition DSRS (Dementia severity Rating scale) questionnaire and SLUMS Scale will be used on all the patients during each visit.

To assess psychiatric co morbidities in dementia patients using HADS (Hospital anxiety and depression scale) will be used.

To improve the quality of life in patient by giving effective counselling to the caregiver

\section{RESULTS AND DISCUSSION}


Average age of the study population was $79.9 \pm 6.1$ and age ranges from $69-89$ years. $12.5 \%$ of the patients were in the age group $\leq 70$ years, $6.3 \%$ were $71-75$ years,31.3\% were in the $76-80$ years and $81-85$ years and $18.8 \%>86$ years. Dementia is mostly observed in the age groups from $76-85$ years and least observed in the age group from 71- 75 .

Table 1: Dementia Patients Age Distribution

\begin{tabular}{lll}
\hline Age in years & Frequency & Percentage \\
\hline$\leq 70$ & 2 & 12.5 \\
$71-75$ & 1 & 6.3 \\
$76-80$ & 5 & 31.3 \\
$81-85$ & 5 & 31.3 \\
$>86$ & 3 & 18.8 \\
Total & 16 & 100.0 \\
\hline
\end{tabular}

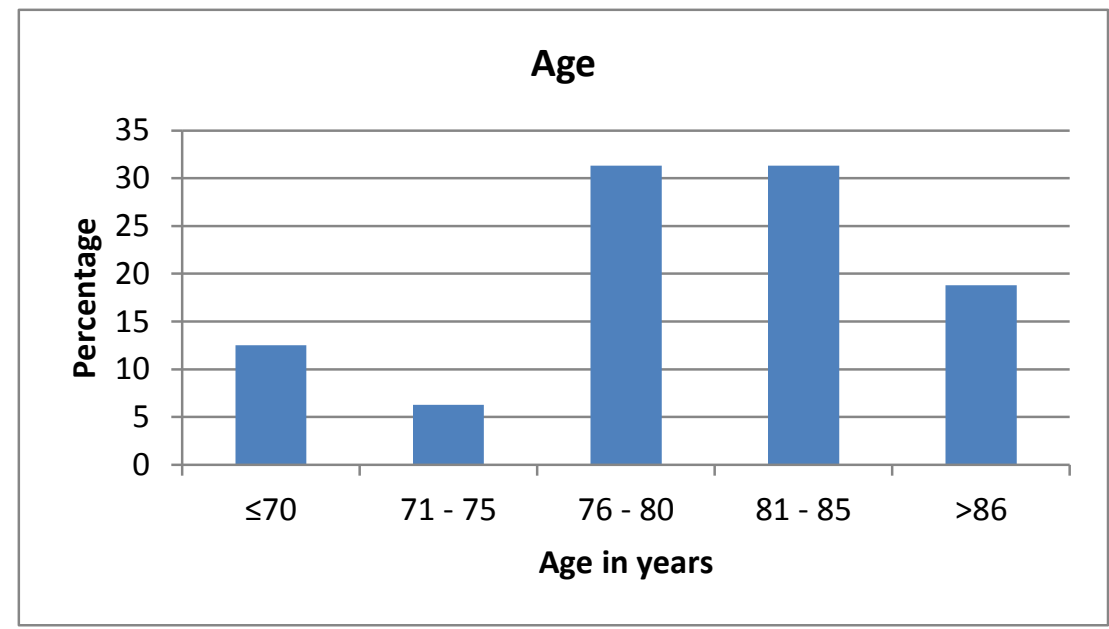

Figure 1: Age Distribution of Dementia Patients.

Table 2: Prevalence of Dementia According To Gender

\begin{tabular}{lll}
\hline Sex & Frequency & Percentage \\
\hline Male & 9 & 56.3 \\
Female & 7 & 43.8 \\
Total & 16 & 100.0 \\
\hline
\end{tabular}

In the gender distribution males dominated in the study population which is $56.3 \%$ while in females it is $43.8 \%$ as depicted in Table .2 




Figure 2: Prevalence of Dementia according to Gender.

Table 3: Education status of Dementia Patients.

\begin{tabular}{lll}
\hline Qualification & Frequency & Percentage \\
\hline Illiterate & 2 & 12.5 \\
High school & 1 & 6.3 \\
Higher secondary & 2 & 12.5 \\
Graduate & 9 & 56.3 \\
Postgraduate and above & 2 & 12.5 \\
Total & 16 & 100.0 \\
\hline
\end{tabular}

Regarding education of patients in the sample, it was noted that $56.2 \%$ of the patients were college graduates, $12.5 \%$ of the patients were high school graduates, $12.5 \%$ were higher secondary graduates and $12.5 \%$ were post graduates and $12.5 \%$ of the patients were illiterate.

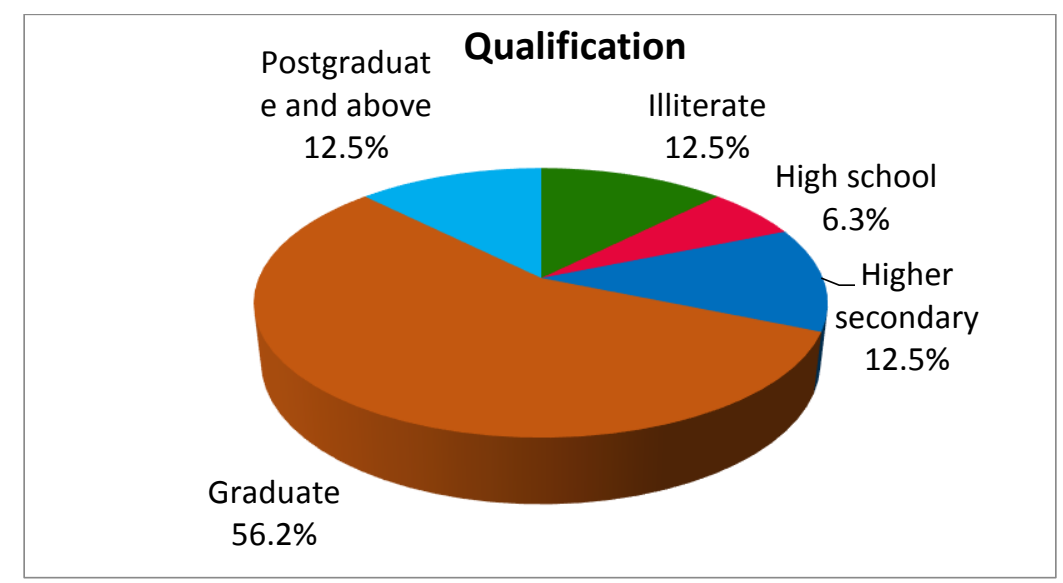

Figure 3: Education status of Dementia patients.

Table 4: Occupation of Dementia Patients

\begin{tabular}{lll}
\hline Occupation & Frequency & Percentage \\
\hline Employed & 7 & 43.8 \\
Business & 4 & 25.0 \\
Manual labour & 1 & 6.3 \\
Unemployed & 4 & 25.0 \\
\hline
\end{tabular}




\begin{tabular}{lll}
\hline Total & 16 & 100.0 \\
\hline
\end{tabular}

Regarding the occupational status of dementia patients, $43.8 \%$ of the patients were employed,25\% of the patients were businessmen, $25 \%$ of them were unemployed and $6.3 \%$ of the patients were manual labour.

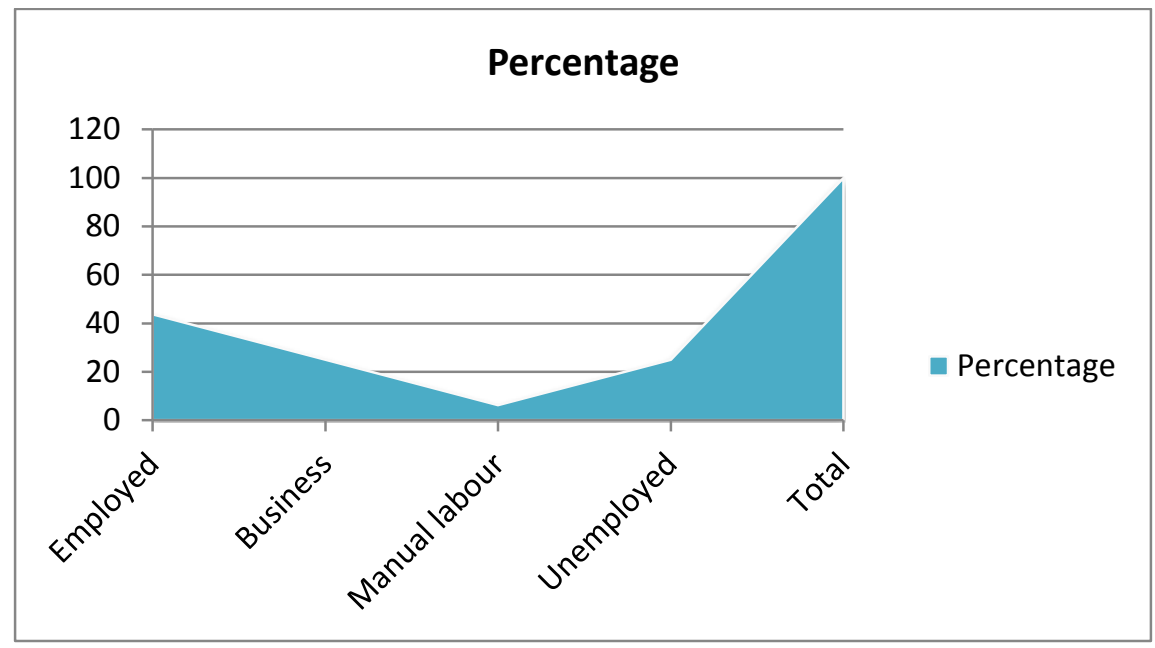

Figure 4: Occupational Status of Dementia Patients

Table 5: Marital status of Dementia Patients

\begin{tabular}{lll}
\hline Marital status & Frequency & Percentage \\
\hline Married & 13 & 81.3 \\
Unmarried & 1 & 6.3 \\
Separated & 1 & 6.3 \\
Widow/Widower & 1 & 6.3 \\
Total & 16 & 100.0 \\
\hline
\end{tabular}

Regarding the marital status of the patients, $81.3 \%$ of the patients were married and $6.3 \%$ of the patients were unmarried, $6.3 \%$ of them were separated and $6.3 \%$ of the patients were widowed.

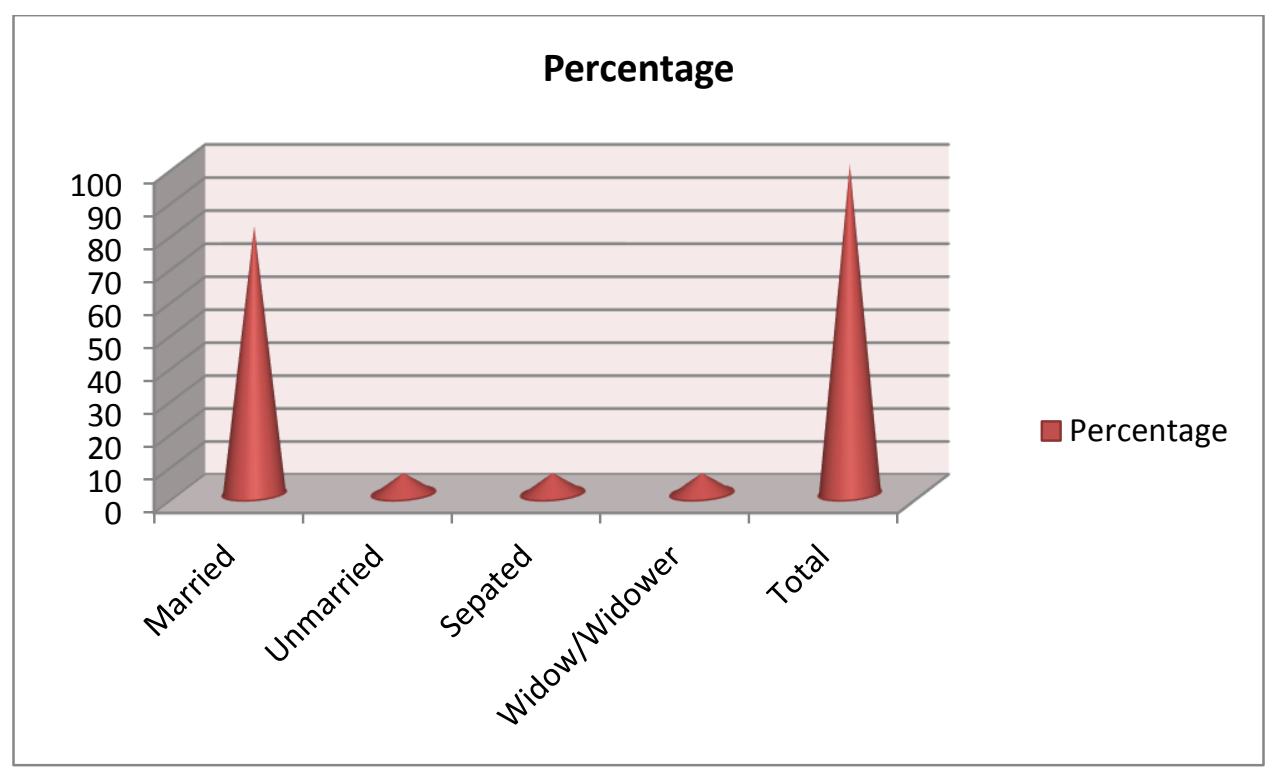


Figure 5: Marital status of Dementia Patients.

Table 6: Socio-Economic status of Dementia Patients.

\begin{tabular}{lll}
\hline SES & Frequency & Percentage \\
\hline Upper & 2 & 12.5 \\
Upper middle & 7 & 43.8 \\
Lower middle & 4 & 25.0 \\
Upper lower & 3 & 18.8 \\
Total & 16 & 100.0 \\
\hline
\end{tabular}

Regarding the socio-economic status of dementia patients, $43.8 \%$ of the patients were of upper class, $43.8 \%$ were of upper middle class, $25 \%$ of the patients were of lower middle class and $18.8 \%$ of the patients were of upper lower class.

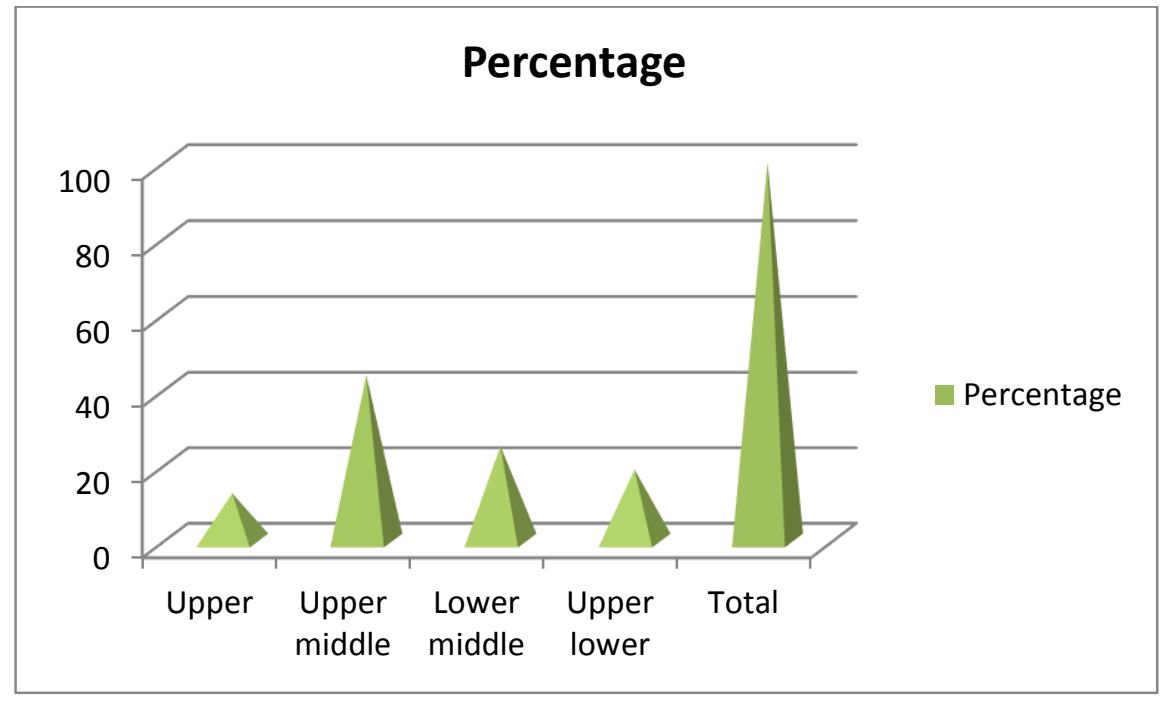

Figure 6: socio-economic status of dementia patients.

Table 7: Depiction of Subtypes Of Dementia

\begin{tabular}{lll}
\hline Type of dementia & Frequency & Percent \\
\hline Alzheimer's disease & 9 & 56.3 \\
Vascular dementia & 3 & 18.8 \\
Lewy body dementia & 1 & 6.3 \\
Fronto-temporal dementia & 1 & 6.3 \\
Beclouded dementia & 1 & 6.3 \\
Subcortical dementia & 1 & 6.3 \\
Total & 16 & 100.0 \\
\hline
\end{tabular}

Out of 16 patients the common type of dementia reported was alzheimers disease found in ,56.3\% of the cases followed by vascular dementia which is found in $18.8 \%$ of the cases followed by lewy body dementia , fronto-temporal dementia and beclouded dementia and sub cortical dementia , which were found to be $6.3 \%$ each. 


\section{Type of dementia}

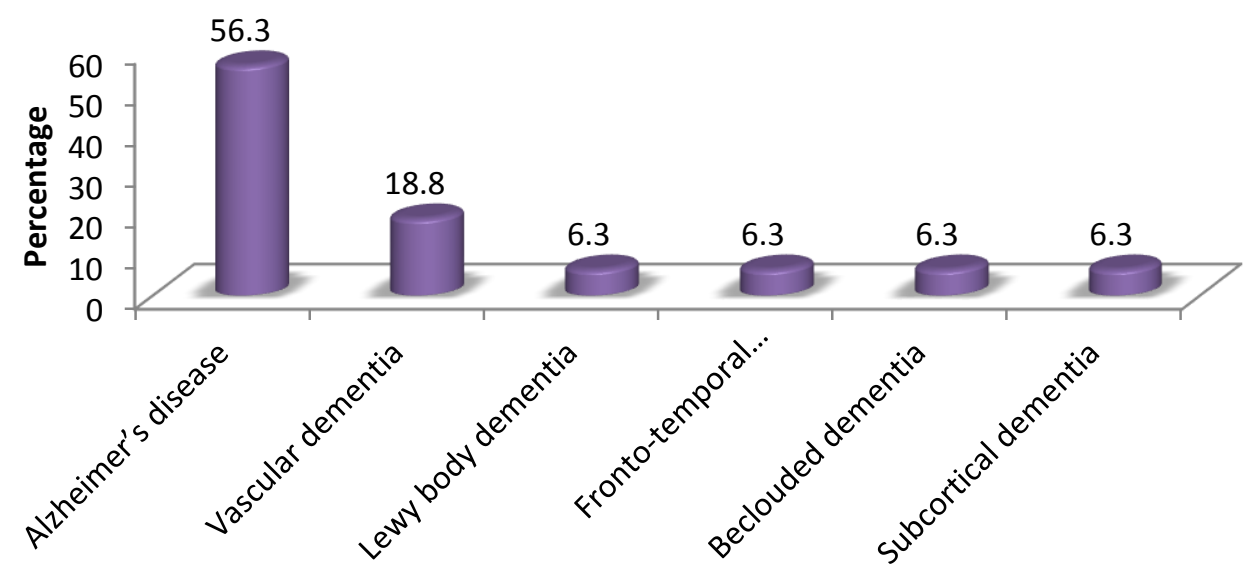

Figure 7: Depiction of Subtypes of Dementia

Table 8: Symptoms Of Dementia

\begin{tabular}{lll}
\hline Symptoms & Frequency & Percentage \\
\hline Forgetting recent events & 16 & 100.0 \\
Unaware of time and place & 10 & 62.5 \\
Difficulty in recognizing relatives & 11 & 68.8 \\
Difficulty in performing familiar task & 5 & 31.3 \\
Lost in familiar places & 7 & 43.8 \\
Poor concentration & 4 & 25.0 \\
Difficulty in communication & 3 & 18.8 \\
Difficulty in walking & 4 & 25.0 \\
Disturbed sleep & 2 & 12.5 \\
Loss of interest & 1 & 6.3 \\
Behavioural changes & 3 & 18.8 \\
Poor judgment & 0 & 0 \\
Mood swing & 8 & 50.0 \\
\hline
\end{tabular}

According to our study we have found out that the most presenting symptom is forgetting recent events with a percent of $100,62.5 \%$ of unaware of time $\&$ place, $68.8 \%$ of difficulty in recognizing relatives, $31.3 \%$ of difficulty in performing familiar task, $43.8 \%$ of lost in familiar places, $25 \%$ of poor concentration, $18.8 \%$ of difficulty in communication, $25 \%$ of difficulty in walking, $12.5 \%$ disturbed sleep, $6.3 \%$ of loss of interest , $18.8 \%$ of behavioural changes, $50 \%$ of mood swings \& also there were no patients presenting with poor judgment. 


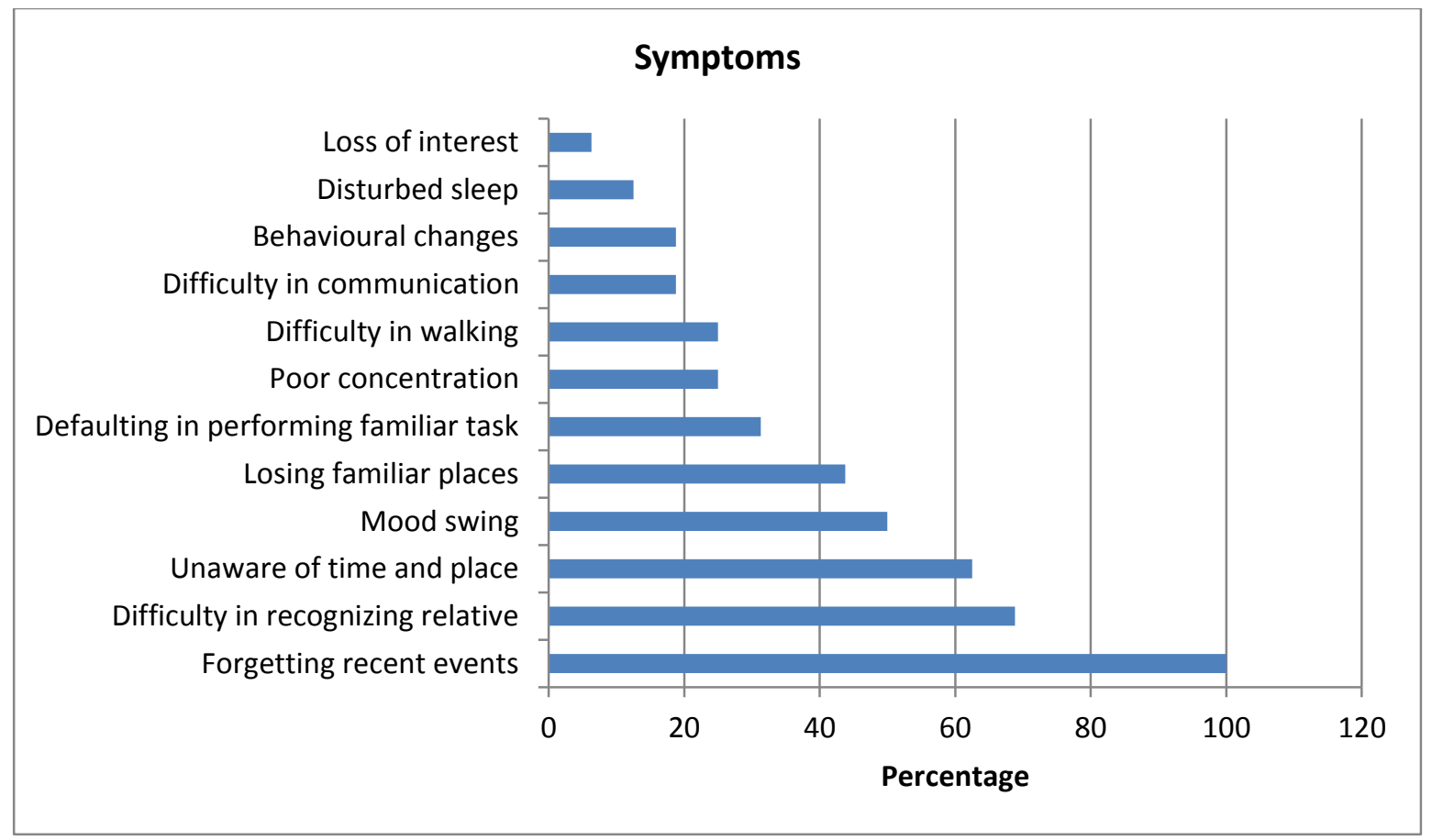

Figure 8: Symptoms of Dementia

Table 9: Representation of comorbidity distribution of dementia patients

\begin{tabular}{lll}
\hline Comorbidities & Frequency & Percentage \\
\hline HTN & 12 & 75.0 \\
DM & 12 & 75.0 \\
CAD & 4 & 25.0 \\
Dyslipidemia & 3 & 18.8 \\
Thyroid & 0 & 0.0 \\
Surgery & 5 & 31.3 \\
Liver disease & 0 & 0.0 \\
Kidney disease & 1 & 6.3 \\
Seizure & 0 & 0.0 \\
Parkinsonism & 2 & 12.5 \\
\hline
\end{tabular}

Distribution of different comorbidities associated with dementia patients is represented in figure 9 . Regarding the comorbidity pattern in dementia patients, it was observed that hypertension and diabetes were found to be the most common type of comobidity. This is about $75 \%$ each, which is followed by surgery and CAD $4.3 \%$ and $25 \%$ respectively . Followed by dyslipidemia $18.8 \%$, parkinsonism $12.5 \%$ and kidney disease $6.3 \%$.None of the patients were having liver disease , thyroid disease or seizure. 




Figure 9: Representation of Comorbidity Distribution of Dementia

Table 10: Representation of Psychiatric Comorbidity Distribution of Dementia

\begin{tabular}{lll}
\hline Psychiatric Co morbidities & Frequency & Percentage \\
\hline Depression & 6 & 37.5 \\
Anxiety & 9 & 56.25 \\
NIL & 1 & 6.25 \\
\hline
\end{tabular}

In total of 16 cases it was observed that $37.5 \%$ of patients was having depression and $56.25 \%$ patients was found to have anxiety, $6.25 \%$ of patients were having neither depression or nor anxiety.



Figure 10: Representation of Psychiatric Comorbidity Distribution Of Dementia 
Table 11: Depection Of Dose Distribution Of Different Drugs Used In Dementia

\begin{tabular}{|c|c|c|c|c|c|c|c|c|}
\hline \multirow[b]{3}{*}{ Drug } & \multirow[b]{3}{*}{$\begin{array}{l}\text { No Of } \\
\text { Patents }\end{array}$} & \multirow[b]{3}{*}{$\%$} & \multicolumn{6}{|l|}{ Dose } \\
\hline & & & $5 \mathrm{mg}$ & & $10 \mathrm{mg}$ & & $1.5 \mathrm{mg}$ & \\
\hline & & & $\begin{array}{l}\text { No .Of } \\
\text { Patients }\end{array}$ & $\%$ & $\begin{array}{l}\text { No. Of } \\
\text { patients }\end{array}$ & $\%$ & $\begin{array}{l}\text { No. Of } \\
\text { patients }\end{array}$ & $\%$ \\
\hline Memantine & 10 & 62.5 & 3 & 18.8 & 7 & 43.8 & & \\
\hline Donepezil & 7 & 43.75 & 3 & 18.8 & 4 & 25.0 & & \\
\hline Rivastigmine & 3 & 18.75 & & & & & 3 & 18.8 \\
\hline
\end{tabular}

Prescription analysis of dementia patients depicts that most popular drug of choice for the given condition was Memantine in a dose range of 5 to $10 \mathrm{mg}$. The doses of drugs used were $5 \mathrm{mg}$ dose in $18.8 \%$ of cases and $10 \mathrm{mg}$ dose in $43.8 \%$ of cases in Memantine, which is followed by Donepezil in a dose range of 5 to $10 \mathrm{mg}$. The doses of drugs used were $5 \mathrm{mg}$ dose in $18.8 \%$ of cases and $10 \mathrm{mg}$ dose in $25.0 \%$ of cases in Donepezil ,while for Rivastigmine it was $1.5 \mathrm{mg}$ dose in $18.8 \%$

Table 12: Prescribing Patterns In Dementia Patients

\begin{tabular}{lll}
\hline Drugs & Frequency & Percentage \\
\hline Memantine & 6 & 37.5 \\
Donepezil & 4 & 25 \\
Memantine+ Donepezil & 3 & 18.75 \\
Rivastigmine & 2 & 12.5 \\
Memantine+ Rivastigmine & 1 & 6.2 \\
Total & 16 & 100 \\
\hline
\end{tabular}

In this study NMDA receptor antagonist, memantine(37.5\%) is the prescribed drug for most of the dementia cases followed by donepezil (25\%),memantine+ donepezil combination (18.75\%), rivastigmine $(12.5 \%)$, memantine+ rivastigmine combination $(6.2 \%)$.

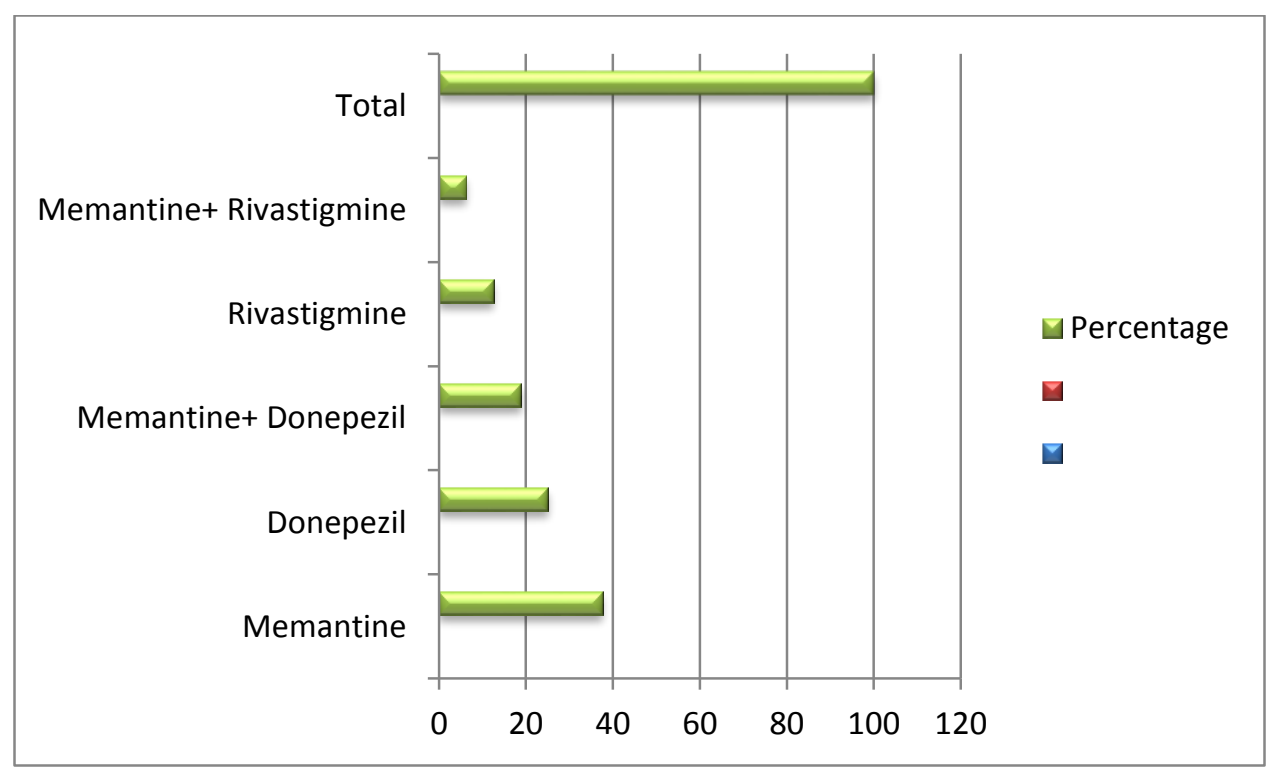

Figure 11: Prescribing Patterns In Dementia Patient 
Table 12: SLUMS Score of Dementia Patients

\begin{tabular}{lll}
\hline SLUMS score & Frequency & Percentage \\
\hline MCI & 1 & 6.3 \\
Dementia & 15 & 93.8 \\
Total & 16 & 100.0 \\
\hline
\end{tabular}

SLUMS scale was conducted to determine whether the patient having dementia or mild cognitive impairment .According to the criteria, about $93.8 \%$ patients was found to have dementia and 6.3 $\%$ having mild cognitive impairment.



Figure 12: Slums Score of Dementia Patients

Table 13: DSRS score of dementia patients.

\begin{tabular}{lll}
\hline DSRS & Frequency & Percentage \\
\hline Mild & 5 & 31.3 \\
Moderate & 8 & 50.0 \\
Severe & 3 & 18.8 \\
Total & 16 & 100.0 \\
\hline
\end{tabular}

Dementia severity rating scale was conducted to determine the severity of dementia.50\% of patients was observed to have moderate dementia followed by $31.3 \%$ patients with mild dementia and $18.8 \%$ patients with severe dementia.

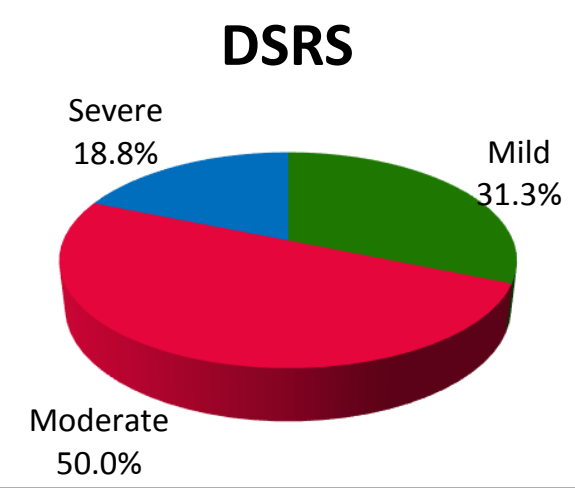

Figure 13: DSRS score of dementia patients 


\section{Table 14: Hads Score In Dementia Patients}

\begin{tabular}{lll}
\hline Hads & Frequency & Percentage \\
\hline Depression & 6 & 36.5 \\
Anxiety & 9 & 56.25 \\
Nil & 1 & 6.3
\end{tabular}

Was conducted in patients to assess the psychiatric comorbidity, In total of 16 cases it was observed that $37.5 \%$ of patients was having depression and $56.25 \%$ patients was found to have anxiety , $6.25 \%$ of patients were having neither depression or nor anxiety



Figure 14: Hads Score In Dementia Patient

\section{DISCUSSION}

Dementia is observed in elderly throughout the world but they are poorly recognized and treated in developing countries including India ${ }^{5}$. The disease important since there are an estimated 35.6 million people with dementia worldwide and more than half of these individuals have Alzheimer's disease (AD) ${ }^{6-9}$ that result in a progressive decline in cognition, function communication and frequent occurrence of neuropsychiatric symptoms. The prescription pattern of drugs used in dementia patients has not been studied much in developing countries where cost may be the most important factor which determine their choice. In this study, we highlight the present Indian scenario of dementia in relation to its severity, comorbidities, and drug utilization in this particular region.

In our study average age of the study population was $79.9 \pm 6.1$ and age ranges from $69-89$ years. Dementia is mostly observed in the age groups from $76-85$ years and least observed in the age group from 71- 75 and males dominated the study population which is $56.3 \%$. In one of the similar study conducted at multiple centers by Gil-N'eciga and Gobartt, it was found that the mean age of patients was $77 \pm 6.6$ years and that female dominated the study population ${ }^{11}$. On contrary, in the study done by Jeschke et al. during the 5-year study period (2004-2008), in 577 patients with 
dementia , 81 years was found to be the median age of the patient and females dominated the study population which is, $69 \%{ }^{10}$. The comparatively lower population of dementia patients in our study might be due to the less preference given to females in the Indian community and therefore neglected and not brought to the hospitals when treatment is essential.

the study it was noted that $56.2 \%$ of the patients were college graduates, $12.5 \%$ of the patients were high school graduates, $12.5 \%$ were higher secondary graduates and $12.5 \%$ were post graduates and $12.5 \%$ of the patients were illiterate. \%. In a similar study conducted by Mansi et al, it was noted that almost $8.0 \%$ of the patients were illiterate. A total of $56.0 \%$ of the patients were high school graduates .The percentage of population who were graduates was $24.0 \%$ while postgraduates were very less $12.0 \%$.

However regarding the Socioeconomic status most of the patients belongs to lower socioeconomic status which may be one of the important risk factors responsible for dementia. In this study it was noted that $12.5 \%$ of the patients were of upper class and $43.8 \%$ of the patients were of upper lower class.

In a study conducted by Qian et al. found that individuals with lower socioeconomic status come into memory clinic after the disease has progressed to dementia, while higher socioeconomic status individuals present earlier when the disease is still in its mild cognitive impairment stage. They concluded that higher socioeconomic status is associated with better cognitive functioning and increased use of cognitive enhancers ${ }^{11}$.

In the present study we found that amongst the types of Dementia the common type of dementia reported was Alzheimers disease found in ,56.3\% of the cases followed by vascular dementia which is found in $18.8 \%$ of the cases followed by lewy body dementia, fronto-temporal dementia and beclouded dementia and sub cortical dementia, which were found to be $6.3 \%$ each. In a clinic-based study from South India also depicts similar results, in which Alzheimer's disease was found to be the commonest in $38.3 \%$ of the cases, vascular dementia in $25.4 \%$ of the cases, followed by fronto temporal dementia (FTD) in $18.7 \%$, Lewy body disease (DLB) in $8.9 \%$, and mixed dementia in $8.6 \%$ of the patients, respectively ${ }^{12}$.

Regarding the comorbidity pattern in dementia patients, it was observed that hypertension and diabetes were found to be the most common type of comorbidity. This is about $75 \%$ each, which is followed by surgery, CAD, dyslipidaemia , parkinsonism and kidney disease respectively. A study reported by Poblador-Plou et al. also found similar results, where the two most frequent comorbidities both for men and women with dementia were hypertension and diabetes. Other comorbidities significantly associated with dementia were Parkinson's disease, congestive heart 
failure, cerebrovascular disease, anemia, cardiac arrhythmia, chronic skin ulcers, osteoporosis, thyroid disease, retinal disorders, prostatic hypertrophy, insomnia and anxiety, and neurosis ${ }^{13}$.In the present study it was observed that $37.5 \%$ of patients was having depression and $56.25 \%$ patients was found to have anxiety , $6.25 \%$ of patients were having neither depression or nor anxiety.

\section{CONCLUSION}

This study shows the drug utilization pattern of dementia patients and also assess the psychiatric comorbidities associated with dementia and quality of life of most of the dementia patients are compromised, it is mainly due to the lack of knowledge about the disease and poor medication taking behaviour of the patients

During our study we provided brief information about the disease to the patients, dietary advice, life style modification measures were given to the patient. Information about each prescribed drug and the importance of taking medication properly were advised to the patient. Data collections are performed through specially designed pro-forma, DSRS questionnaire, HADS questionnaire, SLUMS questionnaire.DSRS and SLUMS scale was used to assess the severity of dementia and HADS scale was used to assess the psychiatric comorbidities. The ratings of these scales were made during each time of patient visit to the doctor.

Pharmacists are in ideal position to provide patient education and optimize the therapeutic outcome. Patient counselling provide a great opportunity to improve the medication adherence of the patient and symptomatic improvement was also observed, further more we also assess the prescribing pattern of dementia in a tertiary care sector from which we came to observe that Memantine is the most commonly prescribed drug in mono-therapy and among combination therapy Memantine-donepezil combination was mostly prescribed.

Our study evaluates the possibility of occurrence of any sort of psychiatric comorbidities with dementia and those patients who were found vulnerable could seek medical care for their condition. The counselling provided was effective in improving the knowledge, attitude and practice of patients with dementia. Pharmacists are in an ideal position to provide patient education and optimize patient care. Greater understanding about the illness and a change of attitude and practice would in turn results in a better therapeutic outcome. For future research the study should be done in a large sample and for long duration of period as a multi-center study.

\section{REFERENCE}

1. Harrison's Principles of Internal Medicine 
2. Alzheimer's Disease International. Policy Brief for G8 Heads of Government. The Global Impact of Dementia 2013-2050. London: Alzheimer's Disease International; 2013.

3. World Health Organization. Dementia: A public health priority. Geneva: World Health Organization; 2012

4. Tampi, R. R., Williamson, D., Muralee, S., Mittal, V., McEnerney, N., Thomas, J., Cash, M. (2011). Behavioral and psychological symptoms of dementia: Part I- epidemiology, neurobiology, heritability and evaluation. Clinical Geriatrics, 19, 1-6.

5. C. P. Ferri, M. Prince, C. Brayne et al., "Global prevalence of dementia: a Delphi consensus study," The Lancet, vol. 366, no.9503, pp. 2112-2117, 2005.

6. V. Chandra, M. Ganguli, R. Pandav, J. Johnston, S. Belle, and S.T. DeKosky, "Prevalence of Alzheimer's disease and other dementias in rural India: the Indo-US study," Neurology, vol. 51,no. 4, pp. 1000-1008, 1998.

7. V. Flaten, C. Laurent, J. E. Coelho et al., "From epidemiology to pathophysiology: what about caffeine in Alzheimer's disease?"Biochemical Society Transactions, vol. 42, no. 2, pp. 587-592,2014.

8. R. George-Carey, D. Adeloye, K. Y. Chan et al., "An estimate of the prevalence of dementia in Africa: a systematic analysis," Journal of Global Health, vol. 2, no. 2,Article ID 020401, 2012.

9. C. Ballard, A. Corbett, and S. Sharp, "Aligning the evidence with practice: NICE guidelines for drug treatment of Alzheimers disease," Expert Review of Neurotherapeutics, vol. 11, no. 3, pp.327-329, 2011.

10. E. Jeschke, T. Ostermann, H. C. Vollmar, M. Tabali, F. Schad, and H. Matthes, "Prescribing patterns in dementia: a multicentre observational study in a German network of CAM physicians," BMC Neurology, vol. 11, article 99, 2011.

11. W. Qian, T. A. Schweizer, and C. E. Fischer, "Impact of socioeconomic status on initial clinical presentation to a memory disorders clinic," International Psychogeriatrics, vol. 26, no. 4,pp. 597-603, 2014.

12. S. Alladi, S.Mekala, S. K. Chadalawada, S. Jala, R.Mridula, and S. Kaul, "Subtypes of dementia: a study from a memory clinic in India," Dementia and Geriatric Cognitive Disorders, vol. 32, no.1, pp. 32-38, 2011.

13. B. Poblador-Plou, A. Calderon-Larranaga, J. Marta-Moreno et al., "Comorbidity of dementia: a cross-sectional study of primary care older patients," BMC Psychiatry, vol. 14, article 84,2014. 
14. E. Gil-N'eciga and A. L. Gobartt, "Treatment pattern of Alzheimer's disease with cholinesterase inhibitors (TRAIN study),"Revista de Neurologia, vol. 46, no. 8, pp. 461464, 2008.

AJPHR is

Peer-reviewed

monthly

Rapid publication

Submit your next manuscript at

editor@ajphr.com / editor.ajphr@gmail.com 